OPEN ACCESS

Edited by:

Qian Yang,

First Affiliated Hospital of Chinese PLA

General Hospital, China

Reviewed by:

Suowen Xu,

University of Science and Technology

of China, China

Yinchuan Xu,

Zhejiang University, China

*Correspondence:

Ning Gu

guning@njucm.edu.cn

TORCID:

Bo Liang

orcid.org/0000-0002-1749-6976

Ning Gu

orcid.org/0000-0003-0704-6768

Specialty section:

This article was submitted to Cardiovascular Therapeutics,

a section of the journal

Frontiers in Cardiovascular Medicine

Received: 29 April 2021

Accepted: 06 July 2021

Published: 06 August 2021

Citation:

Liang B and Gu N (2021) Traditional

Chinese Medicine for Coronary Artery Disease Treatment: Clinical Evidence From Randomized Controlled Trials. Front. Cardiovasc. Med. 8:702110.

doi: 10.3389/fcvm.2021.702110

\section{Traditional Chinese Medicine for Coronary Artery Disease Treatment: Clinical Evidence From Randomized Controlled Trials}

\author{
Bo Liang ${ }^{1 \dagger}$ and Ning Gu ${ }^{2 * \dagger}$ \\ ${ }^{1}$ Nanjing University of Chinese Medicine, Nanjing, China, ${ }^{2}$ Nanjing Hospital of Chinese Medicine Affiliated to Nanjing \\ University of Chinese Medicine, Nanjing, China
}

Traditional Chinese medicine has a history of more than 2,000 years and has been widely used in clinical practice. However, due to the lack of a reliable scientific basis, the role of traditional Chinese medicine in the prevention and treatment of coronary artery disease is not clear. At present, the existing randomized controlled trials about traditional Chinese medicine for coronary artery disease have defects, small sample sizes, and different results, so it is difficult to make a clear conclusion on the actual advantages and disadvantages of traditional Chinese medicine. In this review, the efficacy and safety of traditional Chinese medicine in the prevention and treatment of coronary artery disease were systematically evaluated through randomized controlled trials, most of which were double-blind trials. We reviewed 17 randomized controlled trials that included a total of 11,726 coronary artery disease patients. The methodological quality of the trials was generally high, with nine (52.94\%) having a modified Jadad score of 7 and only three (17.65\%) having a modified Jadad score of $<3$. There are 16 trials (94.12\%) reporting safety; the safety of traditional Chinese medicine seems not to be inferior to that of mimetic, placebo, or western medications. Moreover, the results from 17 randomized controlled trials (100.00\%) showed that traditional Chinese medicine can be applied as a complementary and alternative method to the primary and secondary prevention of coronary artery disease, and only six trials (35.29\%) described adverse cardiovascular events specifically. However, it is necessary to assess the safety and efficacy of traditional Chinese medicine in treating coronary artery disease with long-term hard endpoints.

Keywords: traditional Chinese medicine, coronary artery disease, review, randomized controlled trial, complementary and alternative medicine

\section{INTRODUCTION}

In recent years, due to various reasons, such as an aging population, the number of cardiovascular diseases has risen sharply (1-3). Mortality related to cardiovascular diseases is also rapidly escalating worldwide and brings a great threat to global health (4). Either incidence or mortality of coronary artery disease (CAD) accounts for a large part of cardiovascular diseases (5-7). In the United States, CAD accounts for more than two-thirds of all cardiovascular diseases, and almost half of Americans have at least one risk factor (8). In Europe, cardiovascular mortality was higher 
in middle-income countries where it accounted for a greater proportion of potential years of life lost compared with highincome countries (9). Situations in Asian countries are not better than in western countries (10). Most countries in Asia are experiencing the challenges from CAD, with the mortality rate varying from 103 to 366 per 100,000 adult populations (11). In the clinic, $\mathrm{CAD}$ is often mainly divided into stable CAD (SCAD, namely, chronic myocardial ischemia syndrome) and acute coronary syndrome according to the latest clinical practice guidelines, and the treatment is mainly based on lifestyle management, medical treatment (including conventional western medications and Chinese medicine), and revascularization (12). Despite the use of medical treatment and revascularization, there is still much room for improving efficacy and reducing adverse reactions (13).

Traditional Chinese medicine (TCM), mainly from the East, has shown its idiographic ascendancy in the prevention, therapeutic effect, rehabilitation, and healthcare of diverse diseases (14-16). The evidence-based application of TCM keeps a foothold in China and other Asian countries, and with the popularity of TCM in the East, it is increasingly accepted and used by other countries in the world $(17,18)$. TCM doctors often prescribe a personalized mixture of herbs, characterizing holistic view and syndrome differentiation, to a patient (16). Thus, TCM opens new perspectives for the discovery and development of relevant drugs since it is a more systemic approach to preventing and treating diseases (16), resulting in a rethinking of the importance of TCM (19). So far, more and more randomized controlled trials (RCTs), which are taken to be the gold standard of testing efficacy and safety of therapies for a wide spectrum of diseases and for informing therapeutic guidelines (20), about TCM for CAD have been issued their results. These reliable results not only spur the modernization of TCM but also bring us stronger confidence in the management of CAD. However, we have to admit that RCTs of TCM were carried out relatively late, and these RCTs use surrogate endpoints, have small sample sizes, short follow-up, and diverse outcomes. Here, we critically evaluate the efficacy and safety of TCM in patients with CAD with available evidence from RCTs.

\section{SEARCH STRATEGY AND SELECTION CRITERIA}

Two reviewers (BL and $\mathrm{NG}$ ) searched PubMed, comprising more than 32 million citations for biomedical literature from MEDLINE, Life Science journals, and online books, through the National Center for Biotechnology Information, U.S. National Library of Medicine, for particular RCTs comparing the efficacy and safety of TCM in patients with CAD with language limited to English.

Inclusion criteria for RCTs: (1) Participants with definite diagnoses of $\mathrm{CAD}$, including stable angina, unstable angina, myocardial infarct (MI), SCAD, and coronary artery bypass grafting, made with accepted western medicine methods. (2) The efficacy and/or safety of TCM were assessed. The assessment indicators included, but were not limited to, hard endpoints and surrogate endpoints, such as Chinese medicine syndrome, 6min walking test, ultrasound echocardiography, serum markers, hemodynamic examination, side effects, and cardiovascular mortality. All clinical indicators were compared with no intervention or placebo, or western medications.

Exclusion criteria for RCTs: (1) The sample size was $<50$. (2) The follow-up duration was $<2$ weeks. (3) RCTs only reported symptomatic changes without any objective measurements.

When studies or data duplication were found, only the latest or most complete studies were included. We assessed the trials' methodological quality using the modified Jadad score scale. Two reviewers (BL and NG) extracted the data and assessed quality independently. Any disagreements were resolved by discussion. Extracted information was summarized on standardized reporting forms (Table 1). Although we only included RCTs, which means methodological heterogeneity is acceptable, the clinical heterogeneity is so substantial that we cannot aim to perform a meta-analysis pooling the results.

\section{STABLE ANGINA}

Stable angina is a common symptom of stable CAD (13). The researchers conducted an RCT to assess the efficacy and safety of Wufuxinnaoqing Soft Capsule (五福心脑清胶囊), which has been widely applied to angina for about 30 years, for chronic stable angina (in line with blood stasis syndrome in TCM). It is concluded that Wufuxinnaoqing Soft Capsule could decrease angina attacks and nitroglycerin consumption, relieve angina severity degree, and effectively reduce the blood stasis syndromes after a 12-week treatment, and it was safe during the follow-up (21). Another double-blind RCT of 187 patients with angina after the percutaneous coronary intervention was conducted to confirm the efficacy and safety of Shenzhu Guanxin Recipe (参术冠心方), and the results showed a larger reduction in angina pectoris score, TCM symptom score, and Seattle Angina Questionnaire score in patients given Shenzhu Guanxin Recipe from pretreatment to 12-month follow-up assessment. Again, the data showed that the safety of Shenzhu Guanxin Recipe was acceptable (22). A phase IV double-blind, randomized, and placebo-controlled study conducted at 12 centers in China indicated that after 4-week treatment with Guanxinshutong Capsule (冠心舒通胶囊), the quality of life was substantially improved, and the number of angina attacks and the consumption of short-acting nitrates were significantly reduced (23). Both of these studies were based on the premise of standard western medication treatment with TCM, and there was no positive control group, so the study on Shengjie Tongyu Granule (升解通瘀颗粒) was born. In this study, Tongxinluo Capsule (通心络胶囊), which is clinically recognized as the effective drug in treating angina (25,37-39), was used as a positive control drug to study the effect of Shengjie Tongyu Granule for angina. The results showed that the angina score and TCM score of the two groups were all significantly improved after the treatment, but there was no statistical significance in comparison between groups, suggesting that Shengjie Tongyu Granule can effectively improve the clinical symptoms of patients 
TABLE 1 | Details of major randomized controlled trials.

\begin{tabular}{|c|c|c|c|c|c|c|c|c|c|c|}
\hline References & Patients & $\begin{array}{l}\text { Sample } \\
\text { size }\end{array}$ & Intervention & Comparisons & Outcomes & Follow-up & Efficacy & $\begin{array}{l}\text { Safety } \\
\text { (adverse } \\
\text { events) }\end{array}$ & Blinding & $\begin{array}{l}\text { Modified Jadad } \\
\text { score }\end{array}$ \\
\hline $\begin{array}{l}\text { Zhang et al. } \\
(21)\end{array}$ & $\begin{array}{l}\text { Stable angina (blood } \\
\text { stasis syndrome) }\end{array}$ & 240 & $\begin{array}{l}\text { Wufuxinnaoqing } \\
\text { Soft Capsule }\end{array}$ & Mimetic & $\begin{array}{l}\text { Angina, Chinese medicine syndrome, } \\
\text { the withdrawal or reduce rate of } \\
\text { nitroglycerin }\end{array}$ & 12 weeks & Positive & Yes & Double & $2+2+2+1=7$ \\
\hline Xu et al. (22) & $\begin{array}{l}\text { Angina pectoris after } \\
\text { percutaneous coronary } \\
\text { intervention }\end{array}$ & 187 & $\begin{array}{l}\text { Shenzhu Guanxin } \\
\text { Recipe }\end{array}$ & Placebo & $\begin{array}{l}\text { Angina pectoris score, Chinese } \\
\text { medicine symptom score, and Seattle } \\
\text { angina questionnaire score, the death } \\
\text { rate, restenosis, and other emergency } \\
\text { treatments }\end{array}$ & 12 months & Positive & Yes & Double & $2+2+2+1=7$ \\
\hline Li et al. (23) & Stable angina & 287 & $\begin{array}{l}\text { Guanxinshutong } \\
\text { Capsule }\end{array}$ & Placebo & $\begin{array}{l}\text { The primary outcome in this study is } \\
\text { the change from baseline in angina } \\
\text { attack frequency at } 4 \text { weeks of } \\
\text { treatment. The secondary outcomes } \\
\text { include: (1) reduction of nitroglycerin } \\
\text { dose; (2) score of Seattle angina } \\
\text { questionnaire; (3) positive exercise } \\
\text { tolerance text }\end{array}$ & 4 weeks & Positive & Yes & Double & $2+2+2+1=7$ \\
\hline Zhai et al. (24) & Stable angina & 65 & $\begin{array}{l}\text { Shengjie Tongyu } \\
\text { Granule }\end{array}$ & $\begin{array}{l}\text { Tongxinluo } \\
\text { Capsule }\end{array}$ & $\begin{array}{l}\text { Angina score and traditional Chinese } \\
\text { medicine score }\end{array}$ & 4 weeks & Positive & Yes & $\begin{array}{l}\text { Not } \\
\text { applicable }\end{array}$ & $2+1+0+1=4$ \\
\hline $\begin{array}{l}\text { Wang et al. } \\
\text { (25) }\end{array}$ & Unstable angina & 60 & $\begin{array}{l}\text { Xin'anning Nasal } \\
\text { Drop }\end{array}$ & Control & $\begin{array}{l}\text { The changes of ST segment in resting } \\
\text { electrocardiogram and total ischemia } \\
\text { burden in } 24 \text {-h dynamic } \\
\text { electrocardiogram }\end{array}$ & 4 weeks & Positive & Yes & $\begin{array}{l}\text { Not } \\
\text { applicable }\end{array}$ & $2+1+0+1=4$ \\
\hline Chu et al. (26) & $\begin{array}{l}\text { Unstable angina with } \\
\text { blood stasis syndrome } \\
\text { after percutaneous } \\
\text { coronary intervention }\end{array}$ & 90 & $\begin{array}{l}\text { Xuefu Zhuyu } \\
\text { Capsule }\end{array}$ & $\begin{array}{l}\text { Shengmai Capsule } \\
\text { and placebo }\end{array}$ & $\begin{array}{l}\text { The clinical symptoms and signs, } \\
\text { electrocardiography, and blood stasis } \\
\text { syndrome scores. Short-form } 36 \text { and } \\
\text { Seattle angina questionnaire score. }\end{array}$ & 4 weeks & Positive & Yes & Double & $2+2+2+1=7$ \\
\hline Sun et al. (27) & Unstable angina & 72 & Danhong Injection & $\begin{array}{l}\text { Blood-producing } \\
\text { needle }\end{array}$ & $\begin{array}{l}\text { Homocysteine, high-sensitivity } \\
\text { C-reactive protein, and } \mathrm{N} \text {-terminal } \\
\text { pro-brain natriuretic peptide }\end{array}$ & 2 weeks & Positive & Yes & Single & $1+0+1+1=3$ \\
\hline Lu et al. (28) & $\begin{array}{l}\text { Previous myocardial } \\
\text { infarction }\end{array}$ & 4,870 & Xuezhikang & Placebo & $\begin{array}{l}\text { Major coronary event, total } \\
\text { cardiovascular mortality, total } \\
\text { all-cause mortality, need for coronary } \\
\text { revascularization, and change in } \\
\text { lipoprotein lipids }\end{array}$ & 4.5 years & Positive & Yes & Double & $1+0+1+1=3$ \\
\hline $\begin{array}{l}\text { Shang et al. } \\
\text { (29) }\end{array}$ & Myocardial infarction & 3,505 & $\begin{array}{l}\text { Qi-Shen-Yi-Qi } \\
\text { Dripping Pill }\end{array}$ & Aspirin & $\begin{array}{l}\text { The primary endpoint was a } \\
\text { composite of cardiovascular death, } \\
\text { non-fatal reinfarction, and non-fatal } \\
\text { stroke. The secondary outcomes } \\
\text { were the events of serious cardiac } \\
\text { arrhythmias, heart failure, cardiac } \\
\text { shock, revascularization, pulmonary } \\
\text { embolism, and deep-vein thrombosis }\end{array}$ & 18 months & Positive & Yes & Double & $2+2+2+1=7$ \\
\hline
\end{tabular}


TABLE 1 | Continued

\begin{tabular}{|c|c|c|c|c|c|c|c|c|c|c|}
\hline References & Patients & $\begin{array}{l}\text { Sample } \\
\text { size }\end{array}$ & Intervention & Comparisons & Outcomes & Follow-up & Efficacy & $\begin{array}{l}\text { Safety } \\
\text { (adverse } \\
\text { events) }\end{array}$ & Blinding & $\begin{array}{l}\text { Modified Jadad } \\
\text { score }\end{array}$ \\
\hline $\begin{array}{l}\text { Zhang et al. } \\
\text { (30) }\end{array}$ & $\begin{array}{l}\text { ST segment elevation } \\
\text { myocardial infarction } \\
\text { undergoing emergency } \\
\text { percutaneous coronary } \\
\text { intervention }\end{array}$ & 219 & Tongxinluo & Placebo & $\begin{array}{l}\text { Myocardial no-flow and the infarct } \\
\text { area }\end{array}$ & 6 months & Positive & Yes & Double & $2+2+2+1=7$ \\
\hline Mao et al. (31) & $\begin{array}{l}\text { Acute myocardial } \\
\text { infarction }\end{array}$ & 83 & Danlou Tablet & Placebo & Left ventricular volumes & 90 days & Positive & Yes & Double & $2+1+2+1=6$ \\
\hline Li et al. (23) & $\begin{array}{l}\text { Stable coronary artery } \\
\text { disease }\end{array}$ & 1,500 & $\begin{array}{l}\text { Qing-Xin-Jie-Yu } \\
\text { Granule }\end{array}$ & Placebo & $\begin{array}{l}\text { The primary outcome was a } \\
\text { composite of cardiovascular death, } \\
\text { non-fatal myocardial infarction, and } \\
\text { coronary revascularization }\end{array}$ & 12 months & Positive & Yes & Double & $2+2+2+1=7$ \\
\hline $\begin{array}{l}\text { Zhao et al. } \\
\text { (32) }\end{array}$ & Coronary artery disease & 150 & $\begin{array}{l}\text { Zhibitai } 480 \mathrm{mg}+ \\
\text { atorvastatin } 10 \mathrm{mg}\end{array}$ & $\begin{array}{l}\text { Atorvastatin (20 } \\
\text { and } 40 \mathrm{mg})\end{array}$ & $\begin{array}{l}\text { Lipid profile, cardiotrophin-1, and } \\
\text { C-reactive protein }\end{array}$ & 8 weeks & Positive & Yes & $\begin{array}{l}\text { Not } \\
\text { applicable }\end{array}$ & $2+2+0+1=5$ \\
\hline $\begin{array}{l}\text { Wang et al. } \\
\text { (33) }\end{array}$ & $\begin{array}{l}\text { Stable coronary artery } \\
\text { disease }\end{array}$ & 114 & $\begin{array}{l}\text { Yugengtongyu } \\
\text { Granule }\end{array}$ & Placebo & $\begin{array}{l}\text { Major outcomes (any occurrence of } \\
\text { cardiovascular death, non-fatal } \\
\text { myocardial infarction, or coronary } \\
\text { revascularization), minor outcomes } \\
\text { (any occurrence of all-cause death, } \\
\text { ischemic stroke, readmission due to } \\
\text { unstable angina, heart failure, or } \\
\text { malignant arrhythmia), and composite } \\
\text { outcomes (union of major and minor } \\
\text { outcomes) }\end{array}$ & 18 months & Positive & Yes & Double & $2+2+2+1=7$ \\
\hline Xu et al. (34) & Coronary artery disease & 58 & Huoxin Formula & Control & $\begin{array}{l}\text { Serum biomarkers, and } \\
\text { cardiovascular indicators of the } \\
\text { common and internal carotid arteries }\end{array}$ & 3 months & Positive & Yes & $\begin{array}{l}\text { Not } \\
\text { applicable }\end{array}$ & $1+0+0+1=2$ \\
\hline Ma et al. (35) & $\begin{array}{l}\text { Coronary artery } \\
\text { disease following } \\
\text { percutaneous coronary } \\
\text { intervention and } \\
\text { depression or anxiety }\end{array}$ & 60 & Xinkeshu Tablet & Placebo & $\begin{array}{l}\text { Depressive/anxiety symptoms and } \\
\text { the levels of } 440 \text { peripheral blood } \\
\text { cytokines }\end{array}$ & 12 weeks & Positive & $\begin{array}{l}\text { Not } \\
\text { applicable }\end{array}$ & Double & $2+2+2+1=7$ \\
\hline $\begin{array}{l}\text { Zhang et al. } \\
\text { (36) }\end{array}$ & $\begin{array}{l}\text { Coronary artery disease } \\
\text { received coronary } \\
\text { artery bypass grafting }\end{array}$ & 166 & Shemmai & Control & 6-min walking test & 30 days & Positive & Yes & Single & $2+1+0+1=4$ \\
\hline
\end{tabular}


with angina, with the curative effect similar with Tongxinluo Capsule (24).

\section{UNSTABLE ANGINA}

Unstable angina is a clinical manifestation between exertive stable angina pectoris and acute MI and sudden death. Sixty patients with unstable angina were randomly assigned to two groups to determine the efficacy of add-on therapy of Xin'anning Nasal Drop (心安宁滴鼻剂) for unstable angina, and the results indicated the rapid relief effect of Xin'anning Nasal Drop (40). Another RCT divided a total of 90 unstable angina with blood stasis syndrome in TCM after successful percutaneous coronary intervention population into three groups [Xuefu Zhuyu Capsule (血府逐瘀胶囊) group, Shengmai Capsule (生脉胶囊) group, and placebo group]. After 4 weeks of treatment with corresponding medications, patients in the Xuefu Zhuyu Capsule group had better efficacy on clinical symptoms and signs and blood stasis syndrome scores, and health-related quality of life in those populations compared with those in other groups (26). Sun and his colleagues conducted an RCT that included 72 patients with unstable angina to demonstrate that the treatment of Danhong Injection (丹红注射液) for 2 weeks can reduce homocysteine, high sensitivity C-reactive protein, and $\mathrm{N}$ terminal pro-brain natriuretic peptide of patients with unstable angina (27).

\section{MYOCARDIAL INFARCT}

Nearly 5,000 Chinese patients who experienced a previous MI and average low-density lipoprotein cholesterol levels at baseline were assigned to placebo to Xuezhikang (血脂康) to test the effects of Xuezhikang on lipoprotein and cardiovascular endpoints. After a 4.5-year therapy, Xuezhikang significantly decreased the recurrence of coronary events (including nonfatal MI and death of CAD) and the occurrence of new cardiovascular events as well as total mortality, improved lipoprotein regulation; at the same time, Xuezhikang was safe and well-tolerated (28). Another large sample study aimed to evaluate the effectiveness and safety of Qi-Shen-Yi-Qi Dripping Pill (芪参益气滴丸) for the secondary prevention of MI. After treatment of Qi-Shen-Yi-Qi Dripping Pill or for 1 year, the 1- and 1.5-year estimated incidences of the primary outcome (a composite of cardiovascular death, non-fatal reinfarction, and non-fatal stroke) were 2.98 and $3.67 \%$, respectively, in the Qi-Shen-Yi-Qi Dripping Pill group and 2.96 and 3.81\% in the aspirin group, meaning that the secondary prevention effect of Qi-Shen-Yi-Qi Dripping Pill on MI is similar to that of aspirin although inconclusive (29). A total of 219 patients undergoing emergency percutaneous coronary intervention for acute ST-segment elevation MI were consecutively enrolled in an RCT to evaluate the efficacy of Tongxinluo (通心络) on no-reflow and the infarction area. The results indicated that ST-segment restorations in the Tongxinluo group at 6-, 12, and 24-h reperfusion were more significant than those in the control group. Moreover, the incidence of no-reflow at
$24 \mathrm{~h}$ reperfusion was also significantly reduced. The myocardial perfusion scores on the 7th and 180th days after ST-segment elevation MI in Tongxinluo group were improved significantly compared with those in the control group. The great thing is, there was no significant difference in severe adverse events between the two groups (30). A large proportion of patients with MI have ventricular remodeling later. The prevention or reversal of ventricular remodeling can significantly improve the prognosis and quality of life of those populations. Standard echocardiographic evaluation revealed that compared with placebo, Danlou Tablet (丹萎片) treatment significantly reduced the left ventricular end-systolic and end-diastolic volume indexes in addition to improving the left ventricular ejection fraction. Notably, patients in the Danlou Tablet group had a lower incidence of the major adverse cardiovascular events (31).

\section{STABLE CORONARY ARTERY DISEASE}

Despite optimal secondary preventive treatment, patients with SCAD remain at high risk of cardiovascular events. Patients $(1,500)$ with diagnosed SCAD were assigned to Qing-Xin-JieYu Granule (清心解郁颗粒) or placebo for half a year and followed up for another half a year to determine the reduced risk of cardiovascular events of Qing-Xin-Jie-Yu Granule, and results demonstrated that there was no significant difference in the primary endpoint and adverse events between the QingXin-Jie-Yu Granule group and the placebo group. However, the absolute risk of the composite "hard" endpoint of cardiovascular death, non-fatal MI, and ischemic stroke was reduced by $0.99 \%$ in the Qing-Xin-Jie-Yu Granule group (41). Zhibitai (脂必泰), a Chinese patent medicine for the treatment of hyperlipidemia, can significantly reduce triglycerides, total cholesterol, low-density lipoprotein-cholesterol, and apolipoprotein B with fewer adverse events in patients with SCAD. In addition, Zhibitai released obvious anti-inflammatory effects, reducing cardiotrophin-1, and high-sensitivity C-reactive protein levels (32). Moreover, the addition of Yugengtongyu Granule (愈梗通㾉颗粒) based on current standard treatment reduced the incidence of composite outcomes, defined as any occurrence of cardiovascular death, non-fatal MI, or coronary revascularization, any occurrence of all-cause death, ischemic stroke, readmission due to unstable angina, heart failure, or malignant arrhythmia, and improved quality of life in patients with SCAD (33). Another TCM, Huoxin Formula (活心方), also reduced the highsensitivity C-reactive protein, interleukin 18 , interleukin 17 , and matrix metallopeptidase 9 levels in patients with SCAD (34). Moreover, Huoxin Formula delayed the increase of intima-media thicknesses of the internal carotid artery and common carotid artery, as well as the increase in cardio-ankle vascular index (34). Most patients with SCAD have depression or anxiety symptoms, and this is associated with increased mortality $(42,43)$. Xinkeshu Tablet (心可舒片) can effectively address anxiety and depression symptoms of patients with SCAD via balancing the inflammatory environment-results from a double-blinded, randomized, placebo-controlled, clinical trial (35). 


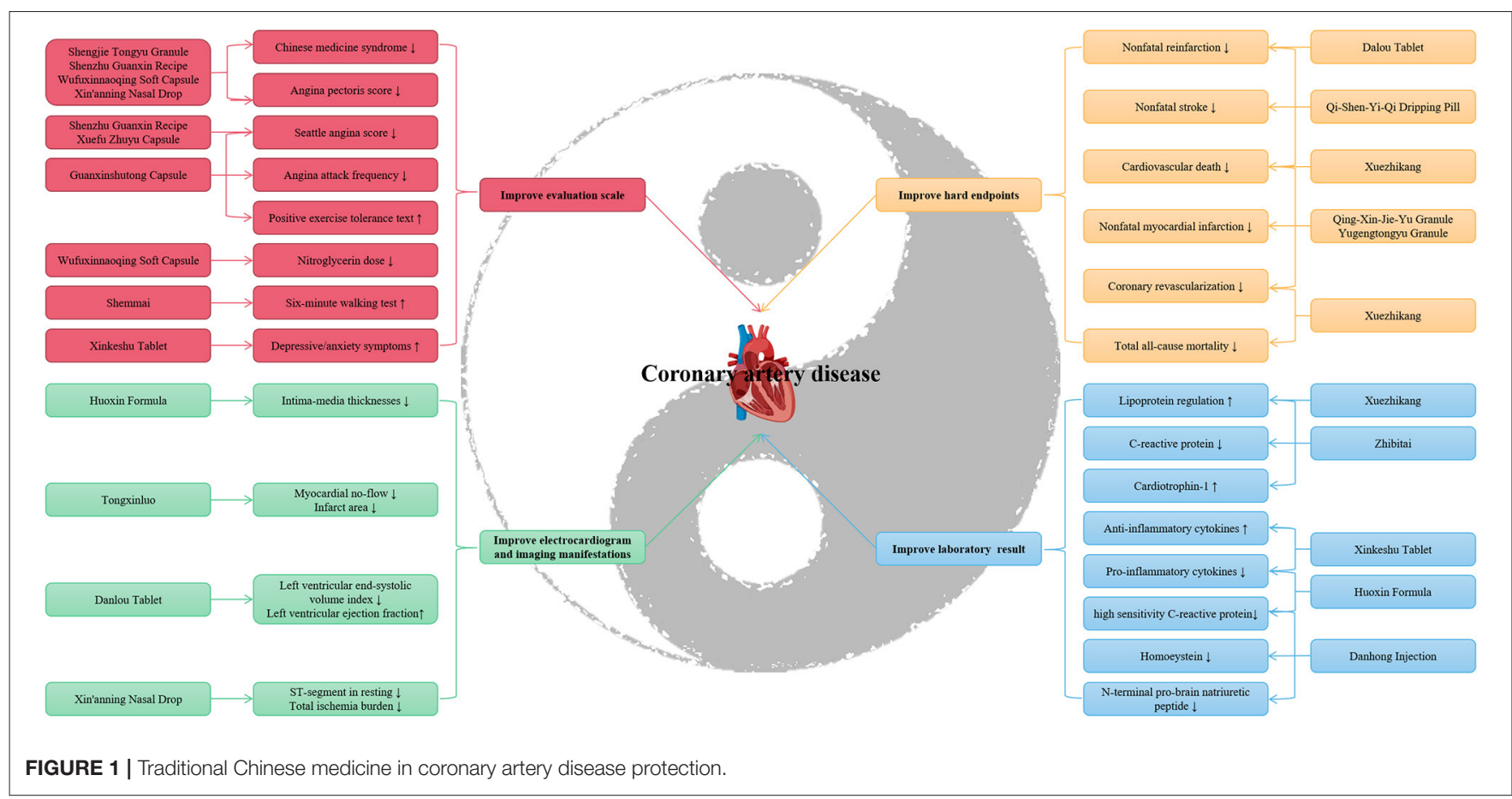

\section{CORONARY ARTERY BYPASS GRAFTING}

Coronary artery bypass grafting is a big blow to the patients, and postoperative cardiac rehabilitation needs to be put on the agenda. Recent research showed that Shenmai approach [Shengmai Injection (参麦注射液) during hospitalization and Shengmai Capsule (参麦胶囊) during 30-day follow-up after discharge combined with cardiac rehabilitation] improved the exercise tolerance of patients who received coronary artery bypass grafting (36).

\section{DISCUSSION}

TCM is a great treasure house of the Chinese nation, and its evidence-based medicine for various diseases, including CAD, is constantly being explored. Here, we systematically reviewed 17 RCTs that included a total of 11,726 patients to reappraise the efficacy and safety of TCM for CAD. The sample sizes ranged from 59 to 4,870 participants, and the mean followup ranged from 2 weeks to 4.5 years. We assessed the trials' quality using the modified Jadad score scale, as described previously (44), and we found that among the 17 RCTs, 9 RCTs (52.94\%) got a full score of seven, and only 3 RCTs $(17.65 \%)$ were identified as low-quality trials because of the less than three score (Table 1). In most RCTs, TCM was associated with significant improvements in surrogate endpoints for stable angina, unstable angina, $\mathrm{MI}, \mathrm{SCAD}$, and coronary artery bypass grafting (Table 1). However, only five trials (29.41\%) described hard endpoints specifically, and only one trial $(5.88 \%)$ did not report safety (Table 1). Although TCM mixture of herbs is the most commonly used in clinics $(20,45,46)$, some herbs can also be prescribed solely (47). An RCT involved
100 patients with CAD demonstrated that Danshen (Salvia miltiorrhiza Bunge) and Gegen [Pueraria montana var. lobata (Willd.) Maesen \& S.M. Almeida ex Sanjappa \& Predeep] adjunctive treatment improved vascular function and structure effectively, and was well tolerated, suggesting they may become a novel secondary prevention approach (48). Interestingly, in addition to Danshen and Gegen, RCTs $(29,49)$ show that QiShen-Yi-Qi Dripping Pill and Tongxinluo Capsule can also be used as a supplementary and alternative therapy for secondary prevention of MI. In general, TCM is notably effective and safe in the prevention, treatment, and health care of CAD compared with mimetic, placebo, or western medications (Table 1 and Figure 1).

Besides traditional Chinese medical (TCM) science also includes Qigong (气功) (50-52). A community-based RCT showed that Baduanjin exercise (八段锦操), a form of Qigong, increased self-efficacy in patients with SCAD, thereby increasing better self-management of the rehabilitation process (53). In addition, some other ongoing RCTs will also provide important evidence-based medicine evidence for TCM in CAD. Inflammation and immune injury in SCAD have been proven (54), and whether Taoren Honghua Jian Granule (桃仁红花 煎颗粒) could alleviate symptoms, control inflammation, and improve quality of life in patients with SCAD will also be explored (55). Other RCTs will reveal the efficacy and safety of Danhong Injection, as well as its optimal timing of intervention (before or after percutaneous coronary intervention) to prevent microvascular obstruction in patients with ST-segment elevation myocardial infarction (56), and determine the clinical efficacy and safety of traditional Chinese medicine Tongxinluo Capsule in the treatment of ST-segment elevation myocardial infarction patients in the reperfusion era (57). 
Our study still has some limits, which should be of concern. First, TCM pays attention to syndrome differentiation, that is to say, the first four diagnoses [Wang (望), Wen (闻), Wen (问), and Qie (切) in TCM] are combined to confirm a syndrome, and then the prescription is conducted according to the syndrome. CAD refers to thoracic obstruction (胸痹) according to TCM (20), and researches show that the common TCM syndromes of CAD are qi and blood deficiency, blood stasis, and obstruction collaterals, liver depression and spleen deficiency, and qi stagnation and blood stasis $(20,58)$. At present, the available RCTs do not fully consider the syndrome differentiation of TCM, which is contrary to TCM. Fortunately, many researchers are conducting RCTs to study the effect of TCM on CAD syndrome, especially qi stagnation and blood stasis syndrome) $(59,60)$ and qi deficiency and blood stasis syndrome (61). The results will provide clinical evidence for the application of TCM to CAD syndrome. Moreover, only Englishpublished RCTs were evaluated, ignoring other languages (6267), which may generate selective bias to a certain degree. Third, the comparisons are control or placebo; the combination of a positive drug and a placebo may be the most acceptable, though it is tedious (68). Moreover, here, we only evaluated the efficacy and safety efficacy of traditional Chinese medicine in stable angina, unstable angina, MI, SCAD, and coronary artery bypass grafting. Although these diseases account for the majority of CAD, they still cannot fully represent CAD. We look forward to more relevant RCTs to show the benefits of TCM on atherosclerosis. Finally, TCM has long been widely applied not only in China but also in other countries, such as Japan, Korea, and other countries. RCTs we reviewed are mainly performed in China, with small sample sizes, short follow-up, and diverse outcomes, from the hard endpoints to surrogate endpoints, rigorously designed trials are warranted.

Although TCM in the treatment of CAD has made gratifying achievements, there is still a long way to go. First, before carrying out the RCT of TCM, especially traditional Chinese medication, we should have enough syndrome differentiation information, preferably from at least three senior chief physicians, so as to be consistent with the theory of TCM and more in line with the clinical application of TCM. Second, because most traditional Chinese medication has certain color and smell, it also imperceptibly increases the difficulty of a blind method setting in

\section{REFERENCES}

1. Zheng X, Curtis JP, Hu S, Wang Y-F, Yang Y-J, Masoudi FA, et al. Coronary catheterization and percutaneous coronary intervention in China: 10-year results from the China PEACE-retrospective CathPCI Study. JAMA Int Med. (2016) 176:512-21. doi: 10.1001/jamainternmed.2016.0166

2. Zhao D, Liu J, Wang M, Zhang X-G, Zhou M-G. Epidemiology of cardiovascular disease in China: current features and implications. Nat Rev Cardiol. (2019) 16:203-12. doi: 10.1038/s41569-018-0119-4

3. Hao P-P, Jiang F, Chen Y-G, Yang J, Zhang K, Zhang M-X, et al. Traditional Chinese medication for cardiovascular disease. Nat Rev Cardiol. (2015) 12:115-22. doi: 10.1038/nrcardio.2014.177

4. Collaborators GBDCoD. Global, regional, and national age-sex-specific mortality for 282 causes of death in 195 countries and territories, 1980-2017: clinical trials. Capsules may be a good choice. Third, in addition to the effectiveness, the safety of traditional Chinese medication is also an issue that needs attention, especially the interaction with western medication. There is still a lack of knowledge about this. In addition, although TCM has been gradually internationalized, we still need to carry out high-quality RCTs abroad to supplement the international evidence of TCM treatment for related diseases, not just CAD, and avoid race and background bias. Finally, TCM is often considered as a supplementary and alternative treatment, but there is also evidence that it can be used as primary and secondary prevention of $\mathrm{CAD}$, which needs a large sample, long follow-up, and high-quality clinical trials with hard endpoint as the outcome to further verify.

In conclusion, the findings from the present study indicate that TCM may be a complementary and alternative agent for the primary and secondary prevention of patients with CAD. Thus, we recommend, at least to an extent, prescribing TCM for CAD, especially in the selected population. However, further rigorously designed trials are warranted to evaluate the effect of TCM on the long-term hard endpoints in patients with CAD.

\section{AUTHOR CONTRIBUTIONS}

BL and NG designed the study, acquired and researched the data for the article, and discussed its content. BL wrote the manuscript and NG revised the manuscript. All authors read and approved the final manuscript.

\section{FUNDING}

This work was funded by the Research and Practice Innovation Plan for Postgraduates of Jiangsu, China (KYCX21_1641), National Natural Science Foundation of China (81774229), Jiangsu Leading Talent Project of Traditional Chinese Medicine (Jiangsu TCM 2018 No.4), and Jiangsu Universities Nursing Advantage Discipline Project (2019YSHL095).

\section{ACKNOWLEDGMENTS}

We thank all relevant published studies. We also thank Yong-Chun Zhu from Nanjing University of Chinese Medicine (Nanjing, China) for his assistance in Figure 1. a systematic analysis for the Global Burden of Disease Study 2017. Lancet. (2018) 392:1736-88. doi: 10.1016/S0140-6736(18)32203-7

5. Liu S-W, Li Y-C, Zeng X-Y, Wang $\mathrm{H}$, Yin $\mathrm{P}$, Wang L-J, et al. Burden of cardiovascular diseases in China, 1990-2016: findings from the 2016 global burden of disease study. JAMA Cardiol. (2019) 4:342-352. doi: 10.1001/jamacardio.2019.0295

6. Shen C-X, Ge J-B. Epidemic of cardiovascular disease in China. Circulation. (2018) 138:342-4. doi: 10.1161/CIRCULATIONAHA.118.033484

7. Chen K-B, Chen K-C, Chang Y-L, Chang K-L, Chang P-C, Chang T-T, et al. In silico investigation of traditional Chinese medicine for potential lead compounds as SPG7 inhibitors against coronary artery disease. Molecules. (2016) 21:588. doi: 10.3390/molecules 21050588

8. Woodruff RC, Casper M, Loustalot F, Vaughan AS. Unequal local progress towards healthy people 2020 objectives for stroke and coronary heart disease 
mortality. Stroke. (2021) 52:e229-232. doi: 10.1161/STROKEAHA.121. 034100

9. Timmis A, Townsend N, Gale CP, Torbica A, Lettino M, Petersen SE, et al. European Society of Cardiology: cardiovascular disease statistics 2019. Eur Heart J. (2020) 41:12-85. doi: 10.1093/eurheartj/ehz859

10. Qiao L, Chen W-Q. Atheroprotective effects and molecular targets of bioactive compounds from traditional Chinese medicine. Pharmacol Res. (2018) 135:212-29. doi: 10.1016/j.phrs.2018.07.012

11. Wong MCS, Zhang DX, Wang HHX. Rapid emergence of atherosclerosis in Asia: a systematic review of coronary atherosclerotic heart disease epidemiology and implications for prevention and control strategies. Curr Opin Lipidol. (2015) 26:257-69. doi: 10.1097/MOL.0000000000000191

12. Knuuti J, Wijns W, Saraste A, Capodanno D, Barbato E, Funck-Brentano C, et al. 2019 ESC Guidelines for the diagnosis and management of chronic coronary syndromes. Eur Heart J. (2020) 41:407-77. doi: 10.1093/eurheartj/ehz425

13. Davies A, Fox K, Galassi AR, Banai S, Ylä-Herttuala S, Lüscher TF. Management of refractory angina: an update. Eur Heart J. (2021) 42:269-83. doi: 10.1093/eurheartj/ehaa820

14. Liang B, Zhu Y-C, Lu J, Gu N. Effects of traditional chinese medicationbased bioactive compounds on cellular and molecular mechanisms of oxidative stress. Oxid Med Cell Longev. (2021) 2021:3617498. doi: $10.1155 / 2021 / 3617498$

15. Hao P-P, Jiang F, Cheng J, Ma L-Y, Zhang Y, Zhao Y-X. Traditional Chinese medicine for cardiovascular disease: evidence and potential mechanisms. J Am Coll Cardiol. (2017) 69:2952-66. doi: 10.1016/j.jacc.2017.04.041

16. Chao J, Dai Y-T, Verpoorte R, Lam W, Cheng Y-C, Pao L-H, et al. Major achievements of evidence-based traditional Chinese medicine in treating major diseases. Biochem Pharmacol. (2017) 139:94-104. doi: 10.1016/j.bcp.2017.06.123

17. Liang B, Zou F-H, Fu L, Liao H-L. Chinese herbal medicine Dingji Fumai decoction for ventricular premature contraction: a real-world trial. BioMed Res Int. (2020) 2020:5358467. doi: 10.1155/2020/5358467

18. Liang B, Zhou Y, Fu L, Liao H-L. Antiarrhythmic mechanisms of Chinese herbal medicine Dingii fumai decoction. Evid Based Complement Alternat Med. (2020) 2020:9185707. doi: 10.1155/2020/9185707

19. Gong P, Li Y, Yao C-Z, Guo H, Hwang H, Liu X-B, et al. Traditional Chinese medicine on the treatment of coronary heart disease in recent 20 years. J Altern Complement Med. (2017) 23:659-66. doi: 10.1089/acm.2016. 0420

20. Liang B, Qu Y, Zhao Q-F, Gu N. Guanxin V for coronary artery disease: a retrospective study. Biomed Pharmacother. (2020) 128:110280. doi: 10.1016/j.biopha.2020.110280

21. Zhang Z-F, Xu F-Q, Liu H-X, Wang F-R, Zhao M-J, Sun L-J, et al. A multicenter, randomized, double-blind clinical study on Wufuxinnaoqing Soft Capsule in treatment of chronic stable angina patients with blood stasis syndrome. Chin J Integr Med. (2015) 21:571-8. doi: 10.1007/s11655-014-1953-9

22. Xu D-P, Wu H-L, Lan T-H, Wang X, Sheng X-G, Lin Y, et al. Effect of Shenzhu Guanxin Recipe on patients with angina pectoris after percutaneous coronary intervention: a prospective, randomized controlled trial. Chin J Integr Med. (2015) 21:408-16. doi: 10.1007/s11655-015-2040-6

23. Li Y, Zhang L, Lv S-Z, Wang X-Z, Zhang J, Tian X-X, et al. Efficacy and safety of oral Guanxinshutong capsules in patients with stable angina pectoris in China: a prospective, multicenter, double-blind, placebo-controlled, randomized clinical trial. BMC Complement Altern Med. (2019) 19:363. doi: 10.1186/s12906-019-2778-Z

24. Zhai G-Y, Dong J-Y, Wang S-G, Shang K-Z. Clinical research on shengjie tongyu granules in the treatment of meteorological cardiovascular disease. $\mathrm{Pak}$ J Pharm Sci. (2015) 28(2 Suppl):785-9.

25. Wu T-X, Harrison RA, Chen X-Y, Ni J, Zhou L-K, Qiao J-Q, et al. Tongxinluo (Tong xin luo or Tong-xin-luo) capsule for unstable angina pectoris. Cochrane Database Syst Rev. (2006) 2006:CD004474. doi: 10.1002/14651858.CD004474.pub2

26. Chu F-Y, Wang J, Yao K-W, Li Z-Z. Effect of Xuefu Zhuyu Capsule on the symptoms and signs and health-related quality of life in the unstable angina patients with blood-stasis syndrome after percutaneous coronary intervention: a Randomized controlled trial. Chin J Integr Med. (2010) 16:399405. doi: 10.1007/s11655-010-9999-9

27. Sun K, Fu C, Nie S-H, You Y. The index and improvement effect of using Danhong injection to patients with atherosclerosis symptoms of coronary heart disease (CHD). Pak J Pharm Sci. (2014) 27(5 Suppl):1699-704.

28. Lu Z-L, Kou W-R, Du B-M, Wu Y-F, Zhao S-P, Brusco OA, et al. Effect of Xuezhikang, an extract from red yeast Chinese rice, on coronary events in a Chinese population with previous myocardial infarction. Am J Cardiol. (2008) 101:1689-93. doi: 10.1016/j.amjcard.2008.02.056

29. Shang H-C, Zhang J-H, Yao C, Liu B, Gao X, Ren M, et al. Qi-shenyi-qi dripping pills for the secondary prevention of myocardial infarction: a randomised clinical trial. Evid Based Complement Alternat Med. (2013) 2013:738391. doi: 10.1155/2013/738391

30. Zhang H-T, Jia Z-H, Zhang J, Ye Z-K, Yang W-X, Tian Y-Q, et al. No-reflow protection and long-term efficacy for acute myocardial infarction with Tongxinluo: a randomized double-blind placebo-controlled multicenter clinical trial (ENLEAT Trial). Chin Med J. (2010) 123:2858-64. doi: 10.3760/cma.j.issn.0366-6999.2010.20.021

31. Mao S, Wang L, Ouyang W-W, Zhou Y-S, Qi J-Y, Guo L-H, et al. Traditional Chinese medicine, Danlou tablets alleviate adverse left ventricular remodeling after myocardial infarction: results of a double-blind, randomized, placebo-controlled, pilot study. BMC Complement Altern Med. (2016) 16:447. doi: 10.1186/s12906-016-1406-4

32. Zhao Y-H, Peng R, Zhao W, Liu Q, Guo Y, Zhao S-P, Xu D-Y. Zhibitai and low-dose atorvastatin reduce blood lipids and inflammation in patients with coronary artery disease. Medicine. (2017) 96:e6104. doi: 10.1097/MD.0000000000006104

33. Wang D-Y, Li C-Y, Xu X-Q, Xu H, Guo C-C, Wang J-P, et al. Effect of Yugengtongyu Granules in patients with stable coronary artery disease on reducing adverse cardiovascular events: a double-blind controlled trial. J Alter Complementary Med. (2021) 27:142-9. doi: 10.1089/acm.2020.0361

34. Xu Y, Hu H-Y, Li Y, Cen R, Yao C-Z, Ma W-H, et al. Effects of huoxin formula on the arterial functions of patients with coronary heart disease. Pharm Biol. (2019) 57:13-20. doi: 10.1080/13880209.2018.1561726

35. Ma H, Wang Y, Xue Y-L, Huang D-Z, Kong Y-J, Zhao X-J, et al. The effect of Xinkeshu tablets on depression and anxiety symptoms in patients with coronary artery disease: Results from a double-blind, randomized, placebo-controlled study. Biomed Pharmacother. (2019) 112:108639. doi: 10.1016/j.biopha.2019.108639

36. Zhang C-X, Zheng Y-G, Chen T, Wang S-Y, Xu M. The utility of traditional Chinese medicine (Shenmai) in the cardiac rehabilitation after coronary artery bypass grafting: a single-center randomized clinical trial. Complement Ther Med. (2019) 47:102203. doi: 10.1016/j.ctim.2019.102203

37. Jia Y-L, Bao F-F, Huang F-Y, Leung S-W. Is tongxinluo more effective than isosorbide dinitrate in treating angina pectoris? A systematic review and meta-analysis of randomized controlled trials. J Alternative Complement Med. (2011) 17:1109-17. doi: 10.1089/acm.2010.0788

38. Mao C, Fu X-H, Yuan J-Q, Yang Z-Y, Chung VCH, Qin Y, et al. Tong-xin-luo capsule for patients with coronary heart disease after percutaneous coronary intervention. Cochrane Database Syst Rev. (2015) 2015:CD010237. doi: 10.1002/14651858.CD0102 37.pub2

39. Jia Y-L, Leung S-W. Comparative efficacy of tongxinluo capsule and betablockers in treating angina pectoris: meta-analysis of randomized controlled trials. J Alter Complement Med. (2015) 21:686-99. doi: 10.1089/acm.2014.0290

40. Wang Z-L, Qian S-M, Zhang H-M. Effect of Xin'anning Nasal Drop in treating coronary heart disease with unstable angina pectoris. Chin J Integr Med. (2006) 12:301-5. doi: 10.1007/s11655-001-0301-Z

41. Li J-G, Gao Z-Y, Zhang L-J, Li S-Y, Yang Q-N, Shang Q-H, et al. Qing-Xin-Jie$\mathrm{Yu}$ Granule for patients with stable coronary artery disease (QUEST Trial): a multicenter, double-blinded, randomized trial. Complement Ther Med. (2019) 47:102209. doi: 10.1016/j.ctim.2019.102209

42. Huffman JC, Celano CM, Beach SR, Motiwala SR, Januzzi JL. Depression and cardiac disease: epidemiology, mechanisms, and diagnosis. Cardiovasc Psychiatry Neurol. (2013) 2013:695925. doi: 10.1155/2013/695925

43. Benko J, Vranková S. Natural psychoplastogens as antidepressant agents. Molecules. (2020) 25:1172. doi: 10.3390/molecules 25051172 
44. Zhang S, Han Y, Xiao Q, Li H, Wu Y. Effectiveness of Bundle Interventions on ICU Delirium: a meta-analysis. Crit Care Med. (2021) 49:335-46. doi: 10.1097/CCM.0000000000004773

45. Liang B, Zhang X-X, Gu N. Virtual screening and network pharmacologybased synergistic mechanism identification of multiple components contained in Guanxin V against coronary artery disease. BMC Complement Med Ther. (2020) 20:345. doi: 10.1186/s12906-020-03133-w

46. Zhang X-X, Shao C-L, Cheng S-Y, Zhu Y, Liang B, Gu N. Effect of Guanxin V in animal model of acute myocardial infarction. BMC Complement Med Ther. (2021) 21:72. doi: 10.1186/s12906-021-03211-7

47. Li Z-M, Xu S-W, Liu P-Q. Salvia miltiorrhizaBurge (Danshen): a golden herbal medicine in cardiovascular therapeutics. Acta Pharmacol Sin. (2018) 39:802-24. doi: 10.1038/aps.2017.193

48. Tam WY, Chook P, Qiao M, Chan LT, Chan TY, Poon YK, et al. The efficacy and tolerability of adjunctive alternative herbal medicine (Salvia miltiorrhiza and Pueraria lobata) on vascular function and structure in coronary patients. J Altern Complement Med. (2009) 15:415-21. doi: 10.1089/acm.2008.0400

49. Li M, Li C-Y, Chen S-Q, Sun Y, Hu J, Zhao C, et al. Tongxinluo capsule potential effectiveness of chinese patent medicine for secondary prevention after acute myocardial infarction: a systematic review and metaanalysis of randomized controlled trials. Front Pharmacol. (2018) 9:830. doi: 10.3389/fphar.2018.00830

50. Zhang Y-P, Hu R-X, Han M, Lai B-Y, Liang S-B, Chen B-J, et al. Evidence base of clinical studies on qi gong: a bibliometric analysis. Complement Ther Med. (2020) 50:102392. doi: 10.1016/j.ctim.2020.102392

51. Wang J, Xiong X. Evidence-based chinese medicine for hypertension. Evidence-Based Complementary Alter Med. (2013) 2013:978398. doi: 10.1155/2013/978398

52. Xiong $\mathrm{X}$. Integrating traditional Chinese medicine into Western cardiovascular medicine: an evidence-based approach. Nat Rev Cardiol. (2015) 12:374. doi: 10.1038/nrcardio.2014.177-c1

53. Xiao X-L, Wang J, Gu Y-M, Cai Y-F, Ma L-X. Effect of community based practice of Baduanjin on self-efficacy of adults with cardiovascular diseases. PLoS ONE. (2018) 13:e0200246. doi: 10.1371/journal.pone.02 00246

54. He X, Liang $\mathrm{B}, \mathrm{Gu} \mathrm{N}$. Th17/Treg imbalance and atherosclerosis. Dis Markers. (2020) 2020:8821029. doi: 10.1155/2020/8 821029

55. Wang Y-R, Zhang Y-Y, Du Y-Y, Yang Y, Wei J, Zhang N, et al. A multicenter, randomized, double-blind, placebo-controlled trial evaluating the efficacy and safety of Taoren Honghua Jian granule in patients with stable coronary artery disease. Medicine. (2019) 98:e17753. doi: 10.1097/MD.000000000 0017753

56. Zhang X-Y, Tian G-H, Shi Z-F, Sun Y, Hu J-Y, Jiang Y, et al. Initiate Danhong Injection before or after percutaneous coronary intervention for microvascular obstruction in ST-elevation myocardial infarction (DIRECTION): study protocol for a randomized controlled trial. Trials. (2020) 21:48. doi: 10.1186/s13063-019-3947-6

57. Xu Y, Li X-D, Zhang H-T, Wu Y, Zhang J, Li J, et al. China Tongxinluo Study for myocardial protection in patients with Acute Myocardial Infarction (CTS-AMI): rationale and design of a randomized, double-blind, placebocontrolled, multicenter clinical trial. Am Heart J. (2020) 227:47-55. doi: 10.1016/j.ahj.2020.06.011

58. Zhao Y-F, Yu X-Y, Cao X-Y, Luo L, He L-Y, Mao S-S, et al. Cluster analysis for syndromes of real-world coronary heart disease with angina pectoris. Front Med. (2018) 12:566-71. doi: 10.1007/s11684-0170556-1
59. Zhao J-N, Zhang Y, Lan X, Chen Y, Li J, Zhang P, et al. Efficacy and safety of Xinnaoning capsule in treating chronic stable angina (qi stagnation and blood stasis syndrome): Study protocol for a multicenter, randomized, double-blind, placebo-controlled trial. Medicine. (2019) 98:e16539. doi: 10.1097/MD.0000000000016539

60. He H-Q, Chen G, Gao J-L, Liu Y, Zhang C-H, Liu C, et al. Xue-Fu-Zhu-Yu capsule in the treatment of qi stagnation and blood stasis syndrome: a study protocol for a randomised controlled pilot and feasibility trial. Trials. (2018) 19:515. doi: 10.1186/s13063-018-2908-9

61. Tian Y, Zhang J-H, Zhao Y-Q, Mao J-Y, Zhu L-P, Gao R, et al. Guanxinjing capsule in the treatment of chronic stable angina: study protocol for a randomized controlled trial. Trials. (2018) 19:577. doi: 10.1186/s13063-018-2950-7

62. Gu CH, Wu YL, Tian SY, Gao X, Qi X, Jia Z, et al. Effect of shensong yangxin capsule on ventricular premature beat and cardiovascular autonomic nervous function in patients with coronary heart disease. Zhongguo Zhong Xi Yi Jie He Za Zhi. (2005) 25:783-6.

63. Wang YA, Yu XJ, Cheng CF, Yang L, Liu F, Zhou MH, et al. Evalation of Jingzhi Xiaoban tablet in improving heart function of coronary heart disease patients by doppler tissue imaging and speckle tracking imaging technology. Zhongguo Zhong Xi Yi Jie He Za Zhi. (2016) 36:399-402.

64. Zhu YF, Luo HM, Deng ZL, Fu DY, Yao W, Dai J. Effects of the Chinese patent medicine, Honghua Injection, on platelet glycoprotein IIb/III a receptors in patients with acute coronary syndrome: a randomized controlled trial. Zhong Xi Yi Jie He Xue Bao. (2012) 10:318-23. doi: 10.3736/jcim20120311

65. Chen P, Zhu CL, Zhang MZ. Effect of tongguan capsule on the number of endothelial progenitor cells in the peripheral blood of patients with coronary artery disease after PCI. Zhongguo Zhong Xi Yi Jie He Za Zhi. (2013) 33:873-7.

66. Lu JQ, He GX, Pan CX, Wen ZH, Zhang YK, Fang XM, et al. Effect of anxin granules combined with tirofiba on patients with acute myocardial infarction after elective percutaneous coronary intervention. Zhongguo Zhong Yao Za Zhi. (2014) 39:920-4.

67. Zhang LF, Wang J, Wang ZJ. Study on clinical intervention of jiawei shengdan louxie sini fang on coronary heart disease with depression. Zhongguo Zhong Yao Za Zhi. (2012) 37:3150-4.

68. Cao H-B, Zhai J-B, Mu W, Lei X, Cao H-X, Liu C-X, et al. Use of comparative effectiveness research for similar Chinese patent medicine for angina pectoris of coronary heart disease: a new approach based on patient-important outcomes. Trials. (2014) 15:84. doi: 10.1186/1745-6215-15-84

Conflict of Interest: The authors declare that the research was conducted in the absence of any commercial or financial relationships that could be construed as a potential conflict of interest.

Publisher's Note: All claims expressed in this article are solely those of the authors and do not necessarily represent those of their affiliated organizations, or those of the publisher, the editors and the reviewers. Any product that may be evaluated in this article, or claim that may be made by its manufacturer, is not guaranteed or endorsed by the publisher.

Copyright (C) 2021 Liang and Gu. This is an open-access article distributed under the terms of the Creative Commons Attribution License (CC BY). The use, distribution or reproduction in other forums is permitted, provided the original author(s) and the copyright owner(s) are credited and that the original publication in this journal is cited, in accordance with accepted academic practice. No use, distribution or reproduction is permitted which does not comply with these terms. 